\title{
EMR is not inferior to ESD for early Barrett's and EGJ neoplasia: An extensive review on outcome, recurrence and complication rates
}

Authors

Institution
Yoriaki Komeda, Marco Bruno, Arjun Koch

Department of Gastroenterology and Hepatology, Erasmus Medical Center, Rotterdam, The Netherlands submitted: 20. August 2013 accepted after revision: 24. February 2014

Bibliography

Dol http://dx.doi.org/

10.1055/s-0034-1365528

Published online: 7.5.2014

Endoscopy International Open 2014; 02: E58-E64

(c) Georg Thieme Verlag KG

Stuttgart · New York

E-ISSN 2196-9736

Corresponding author:

Yoriaki Komeda MD

Department of

Gastroenterology and

Hepatology, Erasmus Medical

Center,

3000 CA Rotterdam

The Netherlands

y-komme@mvb.biglobe.ne.jp
Background and study aims In recent years, it has been reported that early Barrett's and esophagogastric junction (EGJ) neoplasia can be effectively and safely treated using endoscopic mucosal resection (EMR) and endoscopic submucosal dissection (ESD). Multiband mucosectomy (MBM) appears to be the safest EMR method. The aim of this systematic review is to assess the safety and efficacy of MBM compared with ESD for the treatment of early neoplasia in Barrett's or at the EGJ. Methods A literature review of studies published up to May 2013 on EMR and ESD for early Barrett's esophagus (BE) neoplasia and adenocarcinoma at the EGJ was performed through MEDLINE, EMBASE and the Cochrane Library. Results on outcome parameters such as number of curative resections, complications and procedure times are compared and reported.

\section{Introduction}

$\nabla$

The incidence of adenocarcinoma around the esophagogastric junction (EGJ) as a consequence of gastroesophageal reflux disease (GERD) and Barrett's esophagus (BE) has increased in Western countries over the past decades [1]. Esophagectomy has long been regarded as the standard treatment following the detection of high-grade dysplasia (HGD) and early cancer (EC). However, esophagectomy is a complex surgical procedure with a reported mortality rate ranging between $3.0 \%$ and $12.2 \%$ [2]. In recent years, endoscopic mucosal resection (EMR) was introduced for the treatment of HGD and EC (T1(m) adenocarcinoma) in patients with early Barrett's neoplasia with reported 5-year survival rates exceeding 95 $\%$. EMR is far less invasive than surgical resection [3-7] and appears to be safe. The reported perforation rates using a capped-EMR technique range from $5 \%$ to $7 \%[8,9]$. The more recently introduced technique of multiband mucosectomy (MBM) appears to be even safer, with perforation
Results A total of 16 studies met the inclusion criteria for analysis in this study. There were no significant differences in recurrence rates when comparing EMR (10/380, 2.6\%) to ESD (1/333, $0.7 \%$ ) (OR 8.55; 95\%CI, $0.91-80.0, P=0.06$ ). All recurrences after EMR were treated with additional endoscopic resection. The risks of delayed bleeding, perforation and stricture rates in both groups were similar. The procedure was considerably less time-consuming in the EMR group (mean time $36.7 \mathrm{~min}, 95 \% \mathrm{CI}, 34.5-38.9)$ than in the ESD group (mean time $83.3 \mathrm{~min}, 95 \% \mathrm{CI}, 57.4-109.2$ ). Conclusions The MBM technique for EMR is as effective as ESD when comparing outcomes related to recurrence and complication rates for the treatment of early Barrett's or EGJ neoplasia. The MBM technique is considerably less time-consuming.

rates reported in the range of $0 \%$ to $1.2 \%$.[8-23] Importantly, endoscopic resection of early neoplasia in BE is associated with recurrence of metachronous neoplasia in remaining Barrett's mucosa in up to $30 \%$ of cases $[24,25]$. Stepwise radical endoscopic resection (SRER) is a promising technique, particularly when using the MBM technique, and allows larger areas to be resected based on side-by-side piecemeal resections to eradicate not only the neoplastic lesion but all of the Barrett's mucosa. The major drawback of circumferential resection is the high stricture rate. An alternative treatment is endoscopic submucosal dissection (ESD) which was originally introduced for the endoscopic treatment of early gastric cancer in Japan $[26,27]$. ESD was developed for the en-bloc resection of large lesions [28] and enables precise histopathological assessment of specimens [29]. ESD has emerged as the superior technique compared with piecemeal EMR when comparing recurrence rates in the endoscopic treatment of early gastric cancer, achieving overall 5 -year recurrence-free rates of $100 \%$ versus 
$82.5 \%$, respectively.[30] It has recently been reported that ESD is used to treat early Barrett's neoplasia and T1(m) adenocarcinoma at the EGJ [31-36].

To our knowledge, no literature is available which compares the efficacy of both techniques in the setting of distal esophageal and EGJ neoplasia. The aim of this literature review is to assess the safety and efficacy of MBM compared with ESD for the treatment of early neoplasia in Barrett's and at the EGJ. The MBM technique was chosen because we consider this EMR technique to be superior to the capped-EMR technique when comparing perforation rates $[8,9]$.

\section{Methods}

$\nabla$

This literature review entails recently developed EMR techniques performed mainly by a multiband ligator device, [12] but also the cap technique, [37] and free-hand technique [12]. For this purpose, we searched MEDLINE, EMBASE and the Cochrane Library to obtain all studies on EMR and/or ESD for Barrett's esophagus neoplasia and adenocarcinoma at the EGJ that had been published up to May 2013. The following key words were used; "endoscopic mucosal resection (EMR)," "Barrett's esophagus (BE)," "esophageal cancer," "stepwise radical endoscopic resection (SRER)," "multiband mucosectomy (MBM)," "endoscopic submucosal dissection (ESD)," "esophagogastric junction (EGJ)" and "endoscopic mucosal resection (EMR)." All studies were screened according to the following inclusion and exclusion criteria.

In this study, we analyzed the MBM technique in particular because recent literature supports the view that MBM is safe and efficient for Barrett's neoplasia at the EGJ in Western countries. There are no reports including only the MBM technique. MBM was not analyzed in direct comparison to other EMR techniques such as the capped-EMR owing to a lack of literature on other EMR techniques for Barrett's neoplasia.

\section{Inclusion criteria}

1. Studies on Barrett's neoplasia and adenocarcinoma at the EGJ and lower esophagus.

2. Studies at least reporting on the multiband mucosectomy technique in EMR cohorts (multiband mucosectomy, the cap technique and free-hand technique).

3. Studies reporting clinical outcomes on the recurrence rate (local recurrence and distant metastasis), complete eradication rates, curative resection rates, complications (delayed bleeding, perforation and stricture), and procedure times.

\section{Exclusion criteria}

1. Animal experiments

2. Case reports (less than five cases)

3. Review articles

4. Editorials

5. Abstract-only publications

6. Publications in a language other than English

7. Training program

8. Combination therapy with radiofrequency ablation (RFA)

9. Studies with less than 6 months of follow-up

From the studies, we extracted the following information: first author, year of publication, country, research design, number of individuals in the EMR and ESD procedures, intervention types, follow-up period and the clinical outcomes. The reported clinical outcomes were the rates of recurrence (local recurrence and distant metastasis), complete eradication, curative resection, complications (bleeding, perforation and stricture), and procedure time. The term "complete eradication rate" is used to confirm the absence of neoplasia in any of the follow-up biopsy samples after several EMRs had been performed to eradicate Barrett's neoplasia [38]. Curative resection rates are histologically defined by a resection in which the lateral and vertical margins of the specimens are free of cancer and without submucosal invasion beyond the muscularis mucosae, lymphatic invasion, or vascular involvement $[39,40]$.

\section{EMR techniques}

MBM was performed using the Duette Multiband Mucosectomy kit (Cook Endoscopy, Limerick, Ireland). This consists of a transparent cap with six rubber bands and an attachment for releasing wires, and a 5-or 7-Fr hexagonally braided polypectomy snare. After applying markings surrounding the lesion, the tissue is sucked into the cap, and a rubber band is released creating a pseudo-polyp. The snare is placed under the rubber band and the pseudo-polyp is resected using pure coagulation current. The resected specimen is passed into the stomach and the adjacent mucosa subsequently resected in the same fashion until all markings have been included. Finally, the specimens are collected using a retrieval net $[12,22]$. In the cap technique, a flexible oblique cap (diameter $18 \mathrm{~mm}$ ) for en-bloc resection, piecemeal procedures or a standard hard cap (diameter 12.8/14.8/18 mm, MAJ-296/297 or D206 -5, Olympus Europe) are used. After mucosal marking, lesions are lifted by submucosal injection before being sucked into the cap. A preloaded snare in the rim of the cap is then pulled firmly and the lesion resected using EndoCut electrocoagulation [37]. The free-hand technique is a standard lift and snare mucosectomy [10].

\section{ESD technique}

ESD procedures are performed using endo-knives, such as an insulation-tipped knife (IT knife) (KD-610L; Olympus Optical, Tokyo, Japan), IT knife2 (KD-611L; Olympus) or Flex knife (KD630L; Olympus). A transparent hood (D-201-11804; Olympus) is attached to the tip of the endoscope. An electrosurgical generator (ICC200 or VIO300D; [ERBE Tubingen, Germany] or ESG100; [Olympus]) is connected to the endo-knife. Markings along the presumed cutting line are applied around the lesion. A saline solution with epinephrine solution $(0.025 \mathrm{mg} / \mathrm{ml})$ or a mixture of a glycerine solution with normal saline plus $5 \%$ fructose (Glyceol; Chugai Pharmaceutical, Tokyo, Japan) or hyaluronic acid (MucoUp; Johnson \& Johnson Japan, Tokyo, Japan) is injected into the submucosa for lifting. Circumferential cutting is performed using the endo-knife. Subsequent submucosal dissection is performed by using the endo-knife until achieving complete resection of the lesion $[26-28,41,42]$.

\section{Statistical analysis}

The aim of the analysis was to compare the outcomes of two distinct techniques to treat Barrett's esophagus neoplasia and adenocarcinoma at the EGJ, specifically MBM and ESD.

One approach to the analysis would be to use meta-analysis methods to combine the results from the different studies. However, several of the outcomes were binary in nature, and some of these outcomes did not occur in any of the patients in most studies. This prohibits the calculation of standard errors for the prob- 
ability of the outcome occurring, which are required for a metaanalysis.

Instead, the original patient level data were recreated from the summaries reported in each paper. The occurrence of each outcome was compared between techniques using multilevel logistic regression. Two level models were used with individual patients nested within the study.

\section{Results ( $\bullet$ Tables $1-4)$ \\ $\nabla$}

A total of 16 studies met the inclusion criteria for this study. Ten EMR studies originated as follows: five from the Netherlands [8, $17,19,21,22]$, two from Germany [4,12], and one each from the USA [20], UK [23], and Australia [18]. All six ESD studies that met the inclusion were from Japan [31-36]. These studies entailed a total of 761 lesions in the EMR group and 335 lesions in the ESD group. All studies were published between January 2006 and May 2013.

\section{Recurrence rates (local recurrence and distant metastasis) ( $\bullet$ Table 5)}

Eleven studies in both groups $[4,17,18,21,23,31-36]$ reported on recurrence rates. For ESD studies, the mean follow-up time was 28.7 months, while the equivalent number for the EMR studies was 25.6 months. Analysis showed that the recurrence rate was slightly higher in the EMR group (10/380, 2.8\%) compared with the ESD group $(1 / 333,0.3 \%)$, but the difference did not reach statistical significance (odds ratio 8.55; 95\%CI, $0.91-80.0$, $P=0.06$ ). Two cases in the ESD group were excluded on account of having less than 6 months' follow-up.

With regard to EMR procedures, complete eradication rates are described for the SRER procedures [35], while curative resection rates are reported for ESD procedures [36,37]. Complete eradication rate in the EMR group was 363/380 (95.5\%). Curative resection rate in the ESD group was 253/335 (75.5\%). Non-curative resections were mainly because of submucosal invasions of more than $500 \mu \mathrm{m}$ and/or lymphatic and venous invasion. Recurrence of metachronous neoplasia in the EMR group was managed by additional endoscopic resection $[4,17,22]$. One case of distant metastasis was reported in the ESD group where the tumor depth was pT1sm and the patient declined additional surgical treatment [32].

Because of a lack of long-term data on prognosis and disease-free survival in the studies included, the results in this literature review only apply to a relatively short-term prognosis with a mean of 30 months ranging from 8 to 47 months.

\section{Complication rates ( $\bullet$ Table 6$)$}

\section{Delayed bleeding rates}

It proved impossible to compare rates of bleeding during the procedures as the individual definitions of acute bleeding are very different. In many instances, (small) bleedings are considered to be an integral part of the procedure and not a complication. Therefore, we focused on delayed bleeding. Fifteen studies $[4,8$, $12,17,19,20,22,23,31-36]$ reported the occurrence of delayed bleedings with regard to 686 lesions in the EMR group and 335 lesions in the ESD group. The delayed bleeding rate in the EMR group (8/686, $1.2 \%)$ was similar to that in the ESD group (7/335, $2.1 \%$ ), and the difference was not statistically significant (odds ratio 0.46 ; $95 \% \mathrm{CI}, 0.12-1.75, P=0.26$ ). All cases of delayed bleed- ing were effectively managed endoscopically. Blood transfusion was required in three cases [19] in the EMR group and in none in the ESD group.[31 - 34]

\section{Perforation rates}

Fifteen studies $[4,8,12,17,19,20,22,23,31-36]$ reported on perforation rates. The perforation rate in the EMR group $(8 / 686$, $1.2 \%$ ) was similar to that in the ESD group (5/335, $1.5 \%)$, and the difference was not statistically significant (odds ratio 1.07; $95 \% \mathrm{CI}, 0.20-5.62, P=0.94)$. In the EMR group, six patients were managed conservatively with clips (three cases), covered stents (two cases), and observation (one case) [17,22]. Two patients were treated surgically (no detailed description). [8,17] In the ESD group, one patient was managed conservatively with clips [31] and the other four patients were not described [36].

\section{Stricture rates}

Fifteen studies $[4,8,12,17-23,31-35]$ reported on stricture rates with regard to the treatment of 761 lesions in the EMR group and 157 lesions in the ESD group. There were three strictures reported in 456 EMRs for neoplastic lesions alone (no attempt was made to eradicate the whole Barrett's segment). This accounts for a stricture rate of $0.7 \%$ for lesional EMR of only neoplastic areas (odds ratio $0.21 ; 95 \% \mathrm{CI}, 0.03-1.41, P=0.11$ ). The overall stricture rate was higher in the EMR group when all SRER cases were included (170/761, 22.3\%). In the SRER group, the stricture rate was very high $(167 / 305,54.7 \%)$. In the ESD group, seven strictures were reported in 207 cases (7/207, 3.4 $\%)$. These results were similar to those in the EMR group. Symptomatic strictures required intervention with bougienage or balloon dilatation. Two cases in the SRER group were treated surgically on account of perforation after dilatation $[12,17]$.

\section{Procedure times ( $\bullet$ Table 7 )}

Seven studies $[8,22,31,33-36]$ reported on the procedure time including treatment of 82 lesions in the EMR group and 310 lesions in the ESD group. The analysis showed that the procedure time was less time-consuming in the EMR group (mean time $36.7 \mathrm{~min}, 95 \% \mathrm{CI}, 34.5-38.9)$ compared with the ESD group (mean time $83.3 \mathrm{~min}, 95 \% \mathrm{Cl}, 57.4-109.2$ ). The procedure time was analyzed as a continuous variable. To pool the results between different studies, information on the mean procedure time is required for each study as well as either the standard deviation or standard error. Since these data were not available, it is impossible to calculate the statistical significance.

\section{Discussion \\ $\nabla$}

This review demonstrates that, when comparing immediate and short-term outcomes, EMR is not inferior to ESD for the treatment of early Barrett's or EGJ neoplasia. The recurrence rate was slightly higher in the EMR group compared with the ESD group, but the difference was not statistically significant. More importantly, all recurrences in the EMR group were managed by additional endoscopic resections. SRER comprises complete resection to eradicate all intestinal metaplasia at risk of malignant degeneration. In SRER, the complete eradication rate was extremely high (95.5\%). The recurrence rate of intestinal dysplasia after SRER (2.8\%) was superior compared with conventional lesional EMR, which ranged from $14 \%$ to $23 \%$ of cases $[11,40]$. However, these rates included metachronous neoplasia, and as a conse- 
Table 1 Recurrence rates, complete eradication rates/curative resection rates.

\begin{tabular}{|c|c|c|c|c|c|}
\hline Author & Number & Recurrence rate & Follow-up & Range & $\begin{array}{l}\text { Complete } \\
\text { eradication }\end{array}$ \\
\hline \multicolumn{6}{|l|}{ EMR group } \\
\hline Ell et al. 2007 [4] & 100 (EMR) M/C & $6 \%(6 / 100)$ & 33 months (median) & range $2-83$ & $99 \%(99 / 100)$ \\
\hline \multirow[t]{2}{*}{ Moss et al. 2010 [18] } & 75 (EMR) M/C & $0 \%(0 / 35)(\mathrm{CBE})$ & 31 months (mean) & range $3-68$ & $94 \%(33 / 35$ CBE $)$ \\
\hline & 5 not available & $0 \%(0 / 35)$ (non-CBE) & 31 months (mean) & range $3-89$ & $\begin{array}{l}89 \%(31 / 35 \\
\text { non-CBE) }\end{array}$ \\
\hline Thomas et al. 2009 [23] & 16 (EMR) M & $0 \%(0 / 16)$ & 8 months (mean) & IQR 6-12 & $87.5 \%(14 / 16)$ \\
\hline Pouw et al. 2010 [17] & 169 (EMR) M/C/F & $1.8 \%(3 / 169)$ & 32 months (median) & IQR $19-49$ & $95.3 \%(161 / 169)$ \\
\hline van Vilsteren et al. 2011 [21] & 25 (EMR) M/C/F & $4 \%(1 / 25)$ & 25 months (median) & IQR $19-29$ & $100 \%(25 / 25)$ \\
\hline \multicolumn{6}{|l|}{ ESD group } \\
\hline Kakushima et al. 2006 [31] & 30 (ESD) & $\begin{array}{l}0 \%(0 / 28) \text { discarding } 2 \\
\text { cases (follow-up less than } 6 \\
\text { months) }\end{array}$ & 14.6 months (mean) & range $6-31$ & $70 \%(21 / 30)$ \\
\hline Yoshinaga et al. 2008 [32] & 25 (ESD) & $\begin{array}{l}4 \%(1 / 25) \text { including } \\
1 \text { recurrent case (declined } \\
\text { surgery) }\end{array}$ & 36.6 months (median) & range $4-94$ & $72 \%(18 / 25)$ \\
\hline Hirasawa et al. 2010 [33] & 58 (ESD) & $0 \%(0 / 58)$ & 30.6 months (median) & range $1.2-54.9$ & $79 \%(46 / 58)$ \\
\hline Omae et al. 2013 [34] & 44 (ESD) & $0 \%(0 / 44)$ & 33 months (mean) & range $6-64$ & $84.1 \%(37 / 44)$ \\
\hline Imai et al. 2013 [35] & 50 (ESD) & $0 \%(0 / 50)$ & 47 months (median) & range $22-97$ & $72 \%(36 / 50)$ \\
\hline Hoteya et al. 2013 [36] & 128 (ESD) & $0 \%(0 / 128)$ & 34 months (median) & range 2-96 & $74 \%(95 / 128)$ \\
\hline
\end{tabular}

Abbreviations: C, cap; CBE, complete Barrett's excision; F, free hand; IQR, interquartile range; M, multiband mucosectomy.

Table 2 Complication rates.

\begin{tabular}{|c|c|c|c|c|c|}
\hline Author & Number & Delayed bleeding & Perforation & Stricture & Stricture (exclusion of SRER) \\
\hline \multicolumn{6}{|l|}{ EMR group } \\
\hline Soehendra et al. 2006 [12] & 10 (EMR) M & $0 \%(0 / 10)$ & $0 \%(0 / 10)$ & $70 \%(7 / 10)$ & $0 \%(0 / 0)$ \\
\hline Ell et al. 2007 [4] & 100 (EMR) M/C & $0 \%(0 / 100)$ & $0 \%(0 / 100)$ & $0 \%(0 / 100)$ & $0 \%(0 / 100)$ \\
\hline Peters et al. 2007 [22] & 40 (EMR) M & $0 \%(0 / 40)$ & $0 \%(0 / 40)$ & $0 \%(0 / 40)$ & $0 \%(0 / 40)$ \\
\hline Thomas et al. 2009 [23] & 16 (EMR) M & $0 \%(0 / 16)$ & $0 \%(0 / 16)$ & $0 \%(0 / 16)$ & $0 \%(0 / 16)$ \\
\hline Pouw et al. 2010 [17] & 169 (EMR) M/C/F & $1.8 \%(3 / 169)$ & $2.4 \%(4 / 169)$ & $50 \%(84 / 169)$ & $0 \%(0 / 0)$ \\
\hline Moss et al. 2010 [18] & 75 (EMR) M/C & Not available & Not available & $8 \%(6 / 75)$ & $1 \%(1 / 70)$ \\
\hline Pouw et al. 2011 [8] & 42 (EMR) M & $0 \%(0 / 42)$ & $2 \%(1 / 42)$ & $0 \%(0 / 42)$ & $0 \%(0 / 42)$ \\
\hline Alvarez Herrero et al. 2011[19] & 243 (EMR) M & $2 \%(5 / 243)$ & $0 \%(0 / 243)$ & $13 \%(33 / 243)$ & $0 \%(0 / 174)$ \\
\hline Gerke et al. 2011 [20] & 41 (EMR) M/C & $0 \%(0 / 41)$ & $4.9 \%(2 / 41)$ & $44 \%(18 / 41)$ & $14 \%(2 / 14)$ \\
\hline van Vilsteren et al. 2011[21] & 25 (EMR) M/C/F & $0 \%(0 / 25)$ & $4 \%(1 / 25)$ & $88 \%(22 / 25)$ & $0 \%(0 / 0)$ \\
\hline \multicolumn{6}{|l|}{ ESD group } \\
\hline Kakushima et al. 2006 [31] & 30 (ESD) EG] & $0 \%(0 / 30)$ & $3 \%(1 / 30)$ & $3 \%(1 / 30)$ & $3 \%(1 / 30)$ \\
\hline Yoshinaga et al. 2008 [32] & 25 (ESD) EG] & $0 \%(0 / 25)$ & $0 \%(0 / 25)$ & $8 \%(2 / 25)$ & $8 \%(2 / 25)$ \\
\hline Hirasawa et al. 2010 [33] & 58 (ESD) EG] & $5 \%(3 / 58)$ & $0 \%(0 / 58)$ & $2 \%(1 / 58)$ & $2 \%(1 / 58)$ \\
\hline Omae et al. 2013 [34] & 44 (ESD) EGJ & $0 \%(0 / 44)$ & $0 \%(0 / 44)$ & $0 \%(0 / 44)$ & $0 \%(0 / 44)$ \\
\hline Imai et al. 2013 [35] & 50 (ESD) EG] & $6 \%(3 / 50)$ & $0 \%(0 / 50)$ & $6 \%(3 / 50)$ & $6 \%(3 / 50)$ \\
\hline Hoteya et al. 2013 [36] & 126 (ESD) EGJ & $0.7 \%(1 / 128)$ & $3 \%(4 / 128)$ & Not available & Not available \\
\hline
\end{tabular}

quence, it is difficult to compare recurrence rates. All recurrences after EMR and SRER were treated with additional endoscopic resection. This approach to dealing with residual neoplasia is supported by a large German study that states that endoscopic resection should be accepted as the treatment of choice in most patients with high-grade intraepithelial neoplasia (HGIN) and mucosal carcinoma in the esophagus. The rate of complete response was $96.6 \%$, and long-term complete response after re-treatment of metachronous neoplasia (21.5\%) was $94.5 \%$ [43]. Also, endoscopic therapy is highly effective and safe for patients with mucosal adenocarcinoma, with excellent long-term results. In an almost 5-year follow-up of 1000 patients treated with endoscopic resection, there was no mortality and less than $2 \%$ had major complications. This study suggests that endoscopic therapy should become the standard of care for patients with mucosal adenocarcinoma [44]. The results from these studies combined with our current study demonstrate no additional benefits from an oncological point of view of ESD over EMR in the treatment of early Barrett's or EGJ neoplasia.

The risk of delayed bleeding and perforation rates in both groups was similar. Stricture formation is a common complication of endoscopic resection resulting in increased stricture rates with increasing proportions of the diameter resected. The analysis showed that the stricture rate was similar in both groups when comparing resection of the neoplastic lesion alone. Stricture rates increased rapidly in the SRER group when the complete Barrett's mucosa was resected. Likewise, in the ESD group, the post-esophageal stricture rate may increase with larger proportions of the diameter being resected [33]. Symptomatic strictures require intervention via bougienage or balloon dilatation, and are usually easily managed. Unfortunately, the number of dilatation sessions 


\begin{tabular}{|c|c|c|c|c|}
\hline Author & Methods & Procedure time & $\begin{array}{l}\text { Median or } \\
\text { mean }\end{array}$ & $\begin{array}{l}\text { Standard } \\
\text { deviation }\end{array}$ \\
\hline \multicolumn{5}{|l|}{ EMR group } \\
\hline Peters et al. 2007 [22] & 40 (EMR) M & $37 \mathrm{~min}$ (range $28-58$ ) & Median & No \\
\hline Pouw et al. 2011[8] & 42 (EMR) M & $34 \min (I Q R 20-52)$ & Median & No \\
\hline \multicolumn{5}{|l|}{ ESD group } \\
\hline Kakushima et al. 2006 [31] & 30 (ESD) EG] & $70 \mathrm{~min}$ (range $20-120$ ) & Mean & No \\
\hline Hirasawa et al. 2010 [33] & 58 (ESD) EG] & $82 \mathrm{~min}$ (range $22-275$ ) & Mean & No \\
\hline Omae et al. 2013 [34] & 44 (ESD) EG] & 121 min (range $49-272$ ) & Median & No \\
\hline Imai et al. 2013 [35] & 50 (ESD) EG] & 42.5 min (range $10-157$ ) & Median & No \\
\hline Hoteya et al. 2013 [36] & 128 (ESD) EGJ & 102.6 min (range $32.6-171.4$ ) & Mean & No \\
\hline
\end{tabular}

\begin{tabular}{|c|c|c|c|}
\hline Author & Number & Average size (resected specimen) & $\begin{array}{l}\text { Median } \\
\text { or mean }\end{array}$ \\
\hline \multicolumn{4}{|l|}{ EMR group } \\
\hline Soehendra et al. 2006 [12] & $10(\mathrm{M})$ & $\begin{array}{l}14.3 \pm 4.1 \mathrm{~mm}(\text { range } 7-22)(\text { per } \\
\text { specimen }) \text { mean } \times 2 \text { piece }(\text { range } 1-5) \\
\text { median }\end{array}$ & Mean/median \\
\hline Peters et al. 2007 [22] & $40(\mathrm{M})$ & $\begin{array}{l}17 \mathrm{~mm} \text { (SD 6.3) (per specimen) } \\
\times 6 \text { piece (SD 3.5) }\end{array}$ & Mean \\
\hline Moss et al. 2010 [18] & 75 (EMR) M/C & $\begin{array}{l}14 \mathrm{~mm} \text { (range } 9-29) \text { (per specimen) } \\
\times 3 \text { pieces (range } 1-10 \text { ) }\end{array}$ & Mean \\
\hline Thomas et al. 2009 [23] & 16 (EMR) M & $3 \mathrm{~cm}(\mathrm{IQR} 2-5)$ & Median \\
\hline Pouw et al. 2010 [17] & 169 (EMR) M/C/F & $3 \mathrm{~cm}$ (range $2-5)$ & Median \\
\hline Pouw et al. 2011 [8] & $42(\mathrm{M})$ & $\begin{array}{l}18 \mathrm{~mm} \text { (range } 15-20)(\text { per } \\
\text { specimen }) \times 5 \text { piece }(\text { range } 3-7)\end{array}$ & Median \\
\hline Alvarez Herrero et al. 2011 [19] & $243(M)$ & C4M6 cm (IQR C1 - 7 cm, M 3-8) & Median \\
\hline Gerke et al. 2011 [20] & $41(\mathrm{M} / \mathrm{C})$ & $3 \mathrm{~cm}$ (range $1-8)$ & Mean \\
\hline van Vilsteren et al. 2011 [21] & 25 (EMR) M/C/F & $\mathrm{C} 2 \mathrm{M} 4 \mathrm{~cm}$ (range $\mathrm{C} 1-3, \mathrm{M} 2-5$ ) & Median \\
\hline \multicolumn{4}{|l|}{ ESD group } \\
\hline Kakushima et al. 2006 [31] & 30 (ESD) & $40.6 \mathrm{~mm}$ (range $20-80$ ) & Mean \\
\hline Yoshinaga et al. 2008 [32] & 25 (ESD) & $40 \mathrm{~mm}$ (range $25-70$ ) & Mean \\
\hline Hirasawa et al. 2010 [33] & 58 (ESD) & $37.7 \mathrm{~mm}$ (range $14-67)$ & Mean \\
\hline Omae et al. 2013 [34] & 44 (ESD) & $35 \mathrm{~mm}$ (range $15-58$ ) & Mean \\
\hline Imai et al. 2013 [35] & 50 (ESD) & $40.5 \mathrm{~mm}$ (range $24-85$ ) & Median \\
\hline Hoteya et al. 2013 [36] & 128 (ESD) & $21.4 \mathrm{~mm}$ (range $2.6-37.8$ ) & Mean \\
\hline
\end{tabular}

\begin{tabular}{|c|c|c|c|c|c|c|}
\hline \multirow[t]{2}{*}{ Outcome } & \multicolumn{2}{|l|}{ ESD } & \multicolumn{2}{|l|}{ EMR } & \multirow{2}{*}{$\begin{array}{l}\text { Odds ratio } \\
(95 \% \mathrm{Cl})\end{array}$} & \multirow[t]{2}{*}{$P$-value } \\
\hline & No. of studies & $N(\%)$ & No. of studies & $N(\%)$ & & \\
\hline Recurrence rate & 6 & $\begin{array}{l}1 / 333 \\
(0.3 \%)\end{array}$ & 5 & $\begin{array}{l}10 / 380 \\
(2.6 \%)\end{array}$ & $8.55(0.91,80.0)$ & 0.06 \\
\hline
\end{tabular}

Table 4 Average sizes of resected specimens.
Table 3 Procedure times. 
Table 7 Procedure times.

\begin{tabular}{|l|l|l|}
\hline Method & No. of studies & Pooled procedure time $(\mathbf{9 5} \% \mathbf{C l})$ \\
\hline EMR & 2 & $36.7(34.5,38.9)$ \\
\hline ESD & 5 & $83.3(57.4,109.2)$ \\
\hline
\end{tabular}

needed to manage these strictures was not reported in any of these studies.

The major drawback of ESD is the long procedure time, particularly in difficult positions, such as the EGJ. This can be a disadvantage in elderly patients or patients who are unable to undergo lengthy procedures or would require propofol sedation. We were unable to determine a statistically significant difference in procedure times between these two procedures because of the lack of data available on procedure times in the EMR studies. However, there was a huge difference in the small number of studies that did report on procedure times. We therefore believe that it is justified to say that, in general, the EMR procedure takes considerably less time to complete when compared with ESD.

It is difficult to achieve the same level of expertise in ESD techniques in Western countries as in Asian countries, mainly because the incidence of early gastric cancer is very low $[1,45$ 47]. Our review shows that the MBM technique, which is far easier to learn, is safe and as effective in treating early Barrett's or EGJ neoplasia $[8,9,12-23]$.

Some limitations of this literature review should be taken into consideration. First, all studies included were limited by the constraints of a non-randomized design. Second, all studies involved a non-concurrent comparison group. Third, the EMR studies were performed in Western countries, while the ESD studies were performed in Japan. Fourth, there is a lack of long-term data for both sets of studies. Fifth, the definition of therapeutic evaluation after each endoscopic treatment differs between EMR and ESD. Sixth, the results from the EMR studies are fairly heterogeneous and do not always include all parameters that were compared in this review, such as recurrence rates, complication rates, and procedure times. It is because of this that all six ESD papers are compared with different numbers of EMR reports throughout this study. Finally, several studies on EMR originate from a multicenter group, where it is possible that the data might be overlapping in these separate studies.

In conclusion, the MBM technique for EMR appears as effective as ESD when comparing important outcome parameters on the eradication of early Barrett's or EGJ neoplasia. Our review supports the non-inferiority in oncological treatment in the short term where others have confirmed excellent results in the long term. There are no differences in outcome when comparing strictures, bleedings and perforation rates for both EMR and ESD in experienced hands. The MBM technique has considerable advantages in that it is easier to master, and is less time-consuming. Further studies involving randomized, controlled trials with the MBM technique versus ESD in early Barrett's or EGJ neoplasia need to be performed to corroborate these results.

\section{Competing interests: None}

\section{Acknowledgment}

$\nabla$

We would like to thank Paul Bassett for assisting us with the statistical analysis for the purpose of this paper.

\section{References}

1 Lagergren J, Bergström R, Lindgren A et al. Symptomatic gastroesophageal reflux as a risk factor for esophageal adenocarcinoma. $\mathrm{N}$ Engl J Med 1999; 340: 825-831

2 Swisher SG, Deford L, Merriman KW et al. Effect of operative volume on morbidity, mortality, and hospital use after esophagectomy for cancer. J Thorac Cardiovasc Surg 2000; 119: 1126-1132

3 Peters FP, Kara MA, Rosmolen WD et al. Endoscopic treatment of highgrade dysplasia and early stage cancer in Barrett's esophagus. Gastrointest Endosc 2005; 61: 506 - 514

4 Ell C, May A, Pech $O$ et al. Curative endoscopic resection of early esophageal adenocarcinomas (Barrett's cancer). Gastrointest Endosc 2007: 65: $3-10$

5 Pech 0 , Behrens A, May A et al. Long-term results and risk factor analysis for recurrence after curative endoscopic therapy in 349 patients with high-grade intraepithelial neoplasia and mucosal adenocarcinoma in Barrett's oesophagus. Gut 2008; 57: 1200-1206

6 Rice TW, Falk GW, Achkar E et al. Surgical management of high-grade dysplasia in Barrett's esophagus. Am J Gastroenterol 1993; 88: 1832 1836

7 de Boer AG, van Lanschot JJ, van Sandick JW et al. Quality of life after transhiatal compared with extended transthoracic resection for adenocarcinoma of the esophagus. J Clin Oncol 2004; 22: 4202-4208

8 Pouw RE, van Vilsteren FG, Peters FP et al. Randomized trial on endoscopic resection-cap versus multiband mucosectomy for piecemeal endoscopic resection of early Barrett's neoplasia. Gastrointest Endosc $2011 ; 74: 35-43$

9 van Vilsteren FG, Pouw RE, Herrero LA et al. Learning to perform endoscopic resection of esophageal neoplasia is associated with significant complications even within a structured training program. Endoscopy 2012; 44: 4-12

10 Seewald S, Akaraviputh T, Seitz $U$ et al. Circumferential EMR and complete removal of Barrett's epithelium: a new approach to management of Barrett's esophagus containing high-grade intraepithelial neoplasia and intramucosal carcinoma. Gastrointest Endosc 2003; 57: 854-859

11 Giovannini M, Bories E, Pesenti $C$ et al. Circumferential endoscopic mucosal resection in Barrett's esophagus with high-grade intraepithelial neoplasia or mucosal cancer. Preliminary results in 21 patients. Endoscopy 2004; 36: $782-787$

12 Soehendra N, Seewald S, Groth S et al. Use of modified multiband ligator facilitates circumferential EMR in Barrett's esophagus (with video). Gastrointest Endosc 2006; 63: 847-852

13 Peters FP, Kara MA, Rosmolen WD et al. Stepwise radical endoscopic resection is effective for complete removal of Barrett's esophagus with early neoplasia: a prospective study. Am J Gastroenterol 2006; 101: $1449-1457$

14 Larghi A, Lightdale CJ, Ross AS et al. Long-term follow-up of complete Barrett's eradication endoscopic mucosal resection (CBE-EMR) for the treatment of high grade dysplasia and intramucosal carcinoma. Endoscopy 2007; 39: 1086-1091

15 Pouw RE, Peters FP, Sempoux $C$ et al. Stepwise radical endoscopic resection for Barrett's esophagus with early neoplasia: report on a Brussels' cohort. Endoscopy 2008; 40: 892-898

16 Chennat J, Konda VJ, Ross AS et al. Complete Barrett's eradication endoscopic mucosal resection: an effective treatment modality for highgrade dysplasia and intramucosal carcinoma - an American singlecenter experience. Am J Gastroenterol 2009; 104: 2684-2692

17 Pouw RE, Seewald S, Gondrie JJ et al. Stepwise radical endoscopic resection for eradication of Barrett's oesophagus with multi-center series of 169 patients. Gut 2010; 59: $1169-1177$

18 Moss A, Bourke MJ, Hourigan LF et al. Endoscopic resection for Barrett's high-grade dysplasia and early esophageal adenocarcinoma: an essential staging procedure with long-term therapeutic benefit. Am J Gastroenterol 2010; 105: 1276-1283

19 Alvarez HerreroL, Pouw RE, van Vilsteren FG et al. Safety and efficacy of multiband mucosectomy in 1060 resections in Barrett's esophagus. Endoscopy 2011; 43: 177-183

20 Gerke H, Siddiqui J, Nasr I et al. Efficacy and safety of EMR to completely remove Barrett's esophagus: experience in 41 patients. Gastrointest Endosc 2011; 74: 761 - 771

21 van Vilsteren FG, Pouw RE, Seewald S et al. Stepwise radical endoscopic resection versus radiofrequency ablation for Barrett's oesophagus with high-grade dysplasia or early cancer: a multicentre randomised trial. Gut 2011; 60: $765-773$ 
22 Peters FP, Kara MA, Curvers WL et al. Multiband mucosectomy for endoscopic resection of Barrett's esophagus: feasibility study with matched historical controls. Eur J Gastroenterol Hepatol 2007; 19: $311-315$

23 Thomas T, Singh R, Ragunath $K$. Trimodal imaging-assisted endoscopic mucosal resection of early Barrett's neoplasia. Surg Endosc 2009; 23: $1609-1613$

24 Buttar NS, Wang KK, Lutzke LS et al. Combined endoscopic mucosal resection and photodynamic therapy for esophageal neoplasia within Barrett's esophagus. Gastrointest Endosc 2001; 54: 682 -688

25 May A, Gossner L, Pech $O$ et al. Local endoscopic therapy for intraepithelial high-grade neoplasia and early adenocarcinoma in Barrett's oesophagus: acute-phase and intermediate results of a new treatment approach. Eur J Gastroenterol Hepatol 2002; 14: 1085-1091

26 Hirao M, Masuda K, Asanuma T et al. Endoscopic resection of early gastric cancer and other tumors with local injection of hypertonic salineepinephrine. Gastrointest Endosc 1988; 34: 264-269

27 Kodashima S, Fujishiro M, Yahagi $N$ et al. Endoscopic submucosal dissection using flexknife. J Clin Gastroenterol 2006; 40: 378 - 384

28 Saito Y, Uraoka T, Matsuda T et al. Endoscopic treatment of large superficial colorectal tumors: a case series of 200 endoscopic submucosal dissections (with video). Gastrointest Endosc 2007; 66: 966 - 973

29 Gotoda T, Kondo H, Ono $\mathrm{H}$ et al. A new endoscopic mucosal resection procedure using an insulation-tipped electrosurgical knife for rectal flat lesions: report of two cases. Gastrointest Endosc 1999; 50: 560 563

30 Nakamoto S, Sakai Y, Kasanuki J et al. Indications for the use of endoscopic mucosal resection for early gastric cancer in Japan: a comparative study with endoscopic submucosal dissection. Endoscopy 2009; 41: 746-750

31 Kakushima N, Yahagi N, Fujishiro $M$ et al. Efficacy and safety of endoscopic submucosal dissection for tumors of the esophagogastric junction. Endoscopy 2006; 38: $170-174$

32 Yoshinaga S, Gotoda T, Kusano $C$ et al. Clinical impact of endoscopic submucosal dissection for superficial adenocarcinoma located at the esophagogastric junction. Gastrointest Endosc 2008; 67: 202 - 209

33 Hirasawa K, Kokawa A, Oka $\mathrm{H}$ et al. Superficial adenocarcinoma of the esophagogastric junction: long-term results of endoscopic submucosal dissection. Gastrointest Endosc 2010; 72: 960-966

34 Omae M, Fujisaki J, Horiuchi Y et al. Safety, efficacy, and long-term outcomes for endoscopic submucosal dissection of early esophagogastric junction cancer. Gastric Cancer 2013; 16: 147-154
35 Imai K, Kakushima N, Tanaka $M$ et al. Validation of the application of the Japanese curative criteria for superficial adenocarcinoma at the esophagogastric junction treated by endoscopic submucosal dissection: a long-term analysis. Surg Endosc 2013; 27: 2436-2445

36 Hoteya S, Matsui A, Iizuka T et al. Comparison of the clinicopathological characteristics and results of endoscopic submucosal dissection for esophagogastric junction and non-junctional cancers. Digestion 2013; 87: 29-33

37 Inoue $H$, Takeshita $K$, Hori $H$ et al. Endoscopic mucosal resection with a cap-fitted panendoscope for esophagus, stomach, and colon mucosal lesions. Gastrointest Endosc 1993; 39: 58-62

38 Thomas T, Ayaru L, Lee EY et al. Length of Barrett's segment predicts success of extensive endomucosal resection for eradication of Barrett's esophagus with early neoplasia. Surg Endosc 2011; 25: 3627-3635

39 The Paris endoscopic classification of superficial neoplastic lesions: esophagus, stomach, and colon: November 30 to December 1, 2002. Gastrointest Endosc 2003; 58: 3-43

40 Japanese Gastric Cancer Association. Japanese classification of gastric carcinoma - 2nd English Edition. Gastric Cancer 1998; 1: 10-24

41 Oyama T, Tomori A, Hotta K et al. Endoscopic submucosal dissection of early esophageal cancer. Clin Gastroenterol Hepatol 2005; 7: S67-S70

42 Yamamoto $H$, Kawata $H$, Sunada $K$ et al. Success rate of curative endoscopic mucosal resection with circumferential mucosal incision assisted by submucosal injection of sodium hyaluronate. Gastrointest Endosc 2002; 56: $507-512$

43 Pech O, May A, Manner $\mathrm{H}$ et al. Long-term efficacy and safety of endoscopic resection for patients with mucosal adenocarcinoma of the esophagus. Gastroenterology 2014; 146: $652-560$

44 Pech 0 , May A, Rabenstein T et al. Endoscopic resection of early oesophageal cancer. Gut 2007; 56: $1625-1634$

45 Eslick GD. Epidemiology of esophageal cancer. Gastroenterol Clin North Am 2009; 38: 17-25, vii

46 Ballantyne KC, Morris DL, Jones JA et al. Accuracy of identification of early gastric cancer. Br J Surg 1987; 74: 618-619

47 Shimizu S, Tada M, Kawai K. Early gastric cancer: its surveillance and natural course. Endoscopy 1995; 27: 27-31

48 Murata A, Muramatsu K, Ichimiya Y et al. Endoscopic submucosal dissection for gastric cancer in elderly Japanese patients: an observational study of financial costs of treatment based on a national administrative database. J Dig Dis 2014; 15: $62-70$ 